\title{
Improving Tribological Properties of Cast Al-Si Alloys through Application of Wear-Resistant Thermal Spray Coatings
}

\author{
David Culliton, Anthony Betts, Sandra Carvalho, and David Kennedy
}

\author{
(Submitted June 15, 2012; in revised form December 17, 2012)
}

\begin{abstract}
Flame Spray Thermal Spray coatings are low-cost, high-wear surface-treatment technologies. However, little has been reported on their potential effects on cast automotive aluminum alloys. The aim of this research was to investigate the tribological properties of as-sprayed NiCrBSi and WC/12Co Flame Spray coatings applied to two cast aluminum alloys: high-copper LM24 (AISi8Cu3Fe), and low-copper LM25 (AISi7Mg). Potential interactions between the mechanical properties of the substrate and the deposited coatings were deemed to be significant. Microstructural, microhardness, friction, and wear (pin-on-disk, microabrasion, Taber abrasion, etc.) results are reported, and the performance differences between coatings on the different substrates were noted. The coefficient of friction was reduced from 0.69-0.72 to 0.12-0.35. Wear (pin-on-disk) was reduced by a factor of $10^{3}-10^{4}$, which was related to the high surface roughness of the coatings. Microabrasion wear was dependent on coating hardness and applied load. Taber abrasion results showed a strong dependency on the substrate, coating morphology, and homogeneity.
\end{abstract}

Keywords hardness, microscale abrasion, non-ferrous metals, thermal spray coatings, three-body abrasion, two-body abrasion

\section{Introduction}

Thermal spraying is an advanced surface technology for the production of wear, corrosion, and heat-resistant coatings. These surface treatments can be applied as a single- or multiblend coating in homogeneous or functionally gradient structures (Ref 1). Thick coatings $(>1 \mathrm{~mm})$ can be applied over a large area at very high deposition rates, compared with other coating processes such as electroplating, physical vapor deposition (PVD) and chemical vapor deposition (CVD). In addition, these environmentally friendly technologies have been identified as excellent alternatives (Ref 2,3$)$ to the highly toxic (Ref 4) hard chrome plating (HCP) process, traditionally used in the automotive, aerospace, and mining industries. These surface treatments have been shown to have 5-10 times lower human health impacts and 30-50 times lower ecosystem impacts than the HCP process (Ref 5). When

David Culliton and David Kennedy, Department of Mechanical Engineering, Dublin Institute of Technology, Bolton St, Dublin 1, Ireland; Anthony Betts, College of Sciences and Health and Applied Electrochemistry Group, Dublin Institute of Technology, Kevin Street, Dublin 2, Ireland; and Sandra Carvalho, Centro de Física, Universidade do Minho, Campus Azurém, 4800-058 Guimarães, Portugal. Contact e-mails: daveculliton@eircom.net. applied to cast aluminum alloys, they offer the potential of a cost-effective solution with superior wear-resistant surfaces.

Thermal spray technologies include High Velocity OxyFuel (HVOF), a range of plasma spray systems, cold/warm spraying, detonation gun, and flame spraying (FS) methods (Ref 6). These thermal spray processes allow for application of a large array of metals, metal alloys, polymers, and ceramics to almost any bulk material, with flame temperature and particle velocity being the controlling parameters. Significant performance limitations arise as a result of coating quality (porosity, hardness, and adhesive strength), materials costs, and process efficiencies. In particular, porosity can have a substantial impact on the mechanical properties of the coating by imparting anisotropic properties to the coating. This relationship has been quantified, empirically, through the following equation (Ref 7):

$S_{\mathrm{p}}=S_{\mathrm{o}} e^{-b P}$

where $S_{\mathrm{p}}$ is the mechanical property (hardness, Young's Modulus, etc.), $S_{\mathrm{o}}$ is the same property of the bulk material, $b$ is a constant, and $P$ is the porosity level. However, these theoretical models, such as described in Eq 1, are based on idealized microstructures such as uniform spherical, cylindrical, or cubic pores arranged in a cubic array. Therefore, the derived correlations between the effective properties and porosity often cannot be extended to real materials with irregular shapes, nonuniform size, and random distribution of pores. Even then, an increase in porosity would be expected to have a reductive effect on the mechanical properties.

In addition, Kobayashi et al. (Ref 8) have shown that an increase in the hardness:Young's Modulus ratio $\left(H / E_{\mathrm{r}}\right)$ 
of a coating results in an increase in wear resistance. Although the majority of these thermal spray systems require a substantial initial financial outlay, mainly because of equipment and training costs, FS is a low-cost, environmentally friendly, alternative. However, there is a dearth of publications on the potential of FS coatings, particularly on cast aluminum alloys (Al-alloys).

FS coatings are generally easy to apply but tend to develop highly anisotropic properties (Ref 9). This is due to a number of process-related factors. The stackedlamellae structure and related stacking defects generate specific interlamellar features, mainly voids, and unmelted particles within the structure, which may or may not be connected to the upper surface of the deposit (Ref 10). Vapors, quiescent gases in the vicinity of the substrate surface, and peripheral decohesions around lamellae induce interlamellar delaminations. In addition, the rapid solidification of the particles after impact with the surface can result in interlamellar microscopic cracking (Ref 11). The combination of these features generates an interconnected network of voids, often leading to poor wearresistance properties. In the case of hard coating materials, such as NiCrBSi and $\mathrm{WC} / 12 \mathrm{Co}$, this can lead to increased susceptibility to three-body wear mechanisms and a dramatic increase in wear (Ref 12).

The aim of this study was to investigate the potential of low-thickness $(\leq 100 \mu \mathrm{m})$ FS coatings on improving the wear-resistance properties of two cast Al-alloys (Ref 13)-LM24/A1Si8Cu3Fe (high Cu content, and high hardness) and LM25/AlSi7Mg (low $\mathrm{Cu}$ content, and low hardness). This was achieved by improving coating integrity through reduced porosity, reduced in-flight particle oxidation via the use of an inert gas, and increased coating/substrate adhesion.

\section{Experimental}

Flat panels of two Al-alloys-LM24 (A1Si8Cu3Fe) and LM25 (AlSi7Mg) —were cast by Alcast Group, Wexford, Ireland using the gravity die cast process. Compositional analysis was performed on five samples of each alloy using a WAS Foundry Master Arc-spark Optical Emission Spectrometer at CMA, Trinity College, Dublin. Average compositions are detailed in Table 1. All weighing was performed on a Sartorius LA230p precision weighing scale.

\subsection{Sample Preparation}

Test coupons of both alloys were machined to $50 \mathrm{~mm} \times 20 \mathrm{~mm} \times 3 \mathrm{~mm}$. Coupons were then cleaned by grit-blasting $\left(R_{\mathrm{a}}\right.$ of 2-6 $\left.\mu \mathrm{m}\right)$ using a Guyson manual grit blasting machine and white alumina grit, followed by 5-min immersion in acetone in an ultrasonic bath. Samples were coated once air-drying was complete.

\subsection{Coating Application}

Two low-wear FS grade coating materials-NiCrBSi and $\mathrm{WC} / 12 \mathrm{Co}$-were sourced from Castolin Eutectic Ireland Ltd. The coatings were applied using a Castolin Eutectic Castodyn DS8000 Flame Spray gun. The primary compositional constituents of both FS coating materials are provided in Table 1. Both powders had a particle size range of 53-125 $\mu \mathrm{m}$, which is the industry standard powder particle size range for FS application. These powders were produced using the gas atomization process.

To optimize coating deposition, key process parameters were identified and investigated, based on extensive Design of Experiments trials. The intersplat cohesive strength has been shown (Ref 14) to be the principal factor affecting wear performance, and a strong link has been shown to exist between surface roughness, intersplat cohesive strength, and the ratio between in-plane hardness $\left(H_{\mathrm{IP}}\right)$ and out-of-plane hardness $\left(H_{\mathrm{OP}}\right)$ measurements (Ref 15). Those authors concluded that a lower coatingsurface roughness implied flatter splat morphologies and greater intersplat cohesive bonds. This produced a more integrated coating structure, indicated by increased mechanical properties and reduced difference between the in-plane and out-of-plane properties measured. Therefore, high particle speed and in-flight shielding of the molten particles should promote the deposition of a homogeneous coating. The DS8000 facilitates, by design, the use of compressed air to increase the velocity of the in-flight powder particles. By substituting an inert shielding gas (Ref 16, 17), such as Argon, for the compressed air, it was found that there was also an additional reduction in the amount of in-flight oxidation. A range of powder atomizer modules (SSM10, SSM20), designed specifically for the DS8000 unit, were also investigated. The finalized parameters for each coating are provided in Table 2. Oxygen and acetylene were maintained at the recommended pressures of 0.45 and $0.05 \mathrm{MPa}$, respectively. Nominal coating thickness was $100 \mu \mathrm{m}$.

Table 1 Compositions of the cast aluminum alloys and the FS coating materials

\begin{tabular}{lcccccccccccc}
\hline & \multicolumn{10}{c}{ Nominal composition, wt. $\%$} \\
\cline { 2 - 13 } Alloy & Al & Si & Fe & Cu & Mn & Mg & Zn & Ni & Cr & B & WC & Co \\
\hline LM24 & 86.0 & 8.92 & 1.00 & 2.11 & 0.20 & 0.18 & 1.13 & 0.06 & 0.04 & $\ldots$ & $\ldots$ & $\ldots$ \\
LM25 & 92.2 & 6.53 & 0.45 & 0.06 & 0.10 & 0.28 & 0.06 & $<0.01$ & 0.02 & $\ldots$ & $\ldots$ & $\ldots$ \\
NiCrBSi & $\ldots$ & $4-4.5$ & 2.75 & $\ldots$ & $\ldots$ & $\ldots$ & $\ldots$ & $($ Base $)$ & $15-17$ & $3-3.4$ & $\ldots$ & $\ldots$ \\
WC/Co & $\ldots$ & $\ldots$ & $\ldots$ & $\ldots$ & $\ldots$ & $\ldots$ & $\ldots$ & $\ldots$ & $\ldots$ & $\ldots$ & $88(\mathrm{a})$ & 12
\end{tabular}

(a) WC content comprised $5.41 \pm 0.01 \%$ carbon (C) with the balance of the $88 \%$ made up of tungsten (W) 
Table 2 FS application settings

\begin{tabular}{lcccc}
\hline Powder & Denotation & Atomizer module & $\begin{array}{c}\text { Argon flow rate, } \\
\text { nlpm }\end{array}$ & $\begin{array}{c}\text { Powder flow rate, } \\
\mathbf{k g} / \mathbf{h}\end{array}$ \\
\hline NiCrBSi & f625 & SSM20 & 9 & 3 \\
WC/Co & fWC/Co & SSM10 & 9 & 2 \\
\hline
\end{tabular}

Coatings applied to LM24 are denoted with (24) while those applied to LM25 are denoted by (25).

\subsection{Microstructural Analysis}

Samples were sectioned, mounted, ground, and polished to characterize the substrate, coating, and interface. Samples $\left(1 \mathrm{~cm}^{2}\right)$ were mounted in an Epomet $\mathrm{F}$ resin using a Buehler SimpliMet ${ }^{\circledR} 3000$ Automatic Mounting Press. The heating/cooling processes were $8 \mathrm{~min} / 4 \mathrm{~min}$, respectively. Grinding was performed on a Buehler Metaserv automatic grinder/polisher with pro-rotation at $50 \mathrm{rpm}$ and a total constant pressure of $200 \mathrm{~N}$. Grinding steps ran for $3.5 \mathrm{~min}$, while polishing and final polishing steps ran for $3.0 \mathrm{~min}$. Grinding was performed, consecutively, at $240,600,800$, and 1200 grit paper. This was followed by polishing at 9,6 , and $3 \mu \mathrm{m}$. Final polishing was performed using $0.05 \mu \mathrm{m}$ paste.

Microstructural analysis was performed on a ReichertJung Me3 metallurgical microscope and an Olympus BX60M metallurgical microscope. Metallographic analysis, coating thickness measurements, and porosity measurements were performed, using image analysis techniques. A minimum of five samples per system (coating/substrate alloy) were tested.

\subsection{Tribological and Mechanical Techniques}

Coated samples were subjected to a number of tribological and mechanical property tests to characterize the coatings and determine coating/substrate alloy composite properties. For all tests which required a cros- sectional area (csa), the samples were prepared as per Sect. 2.3.

Bond-Strength testing was performed using the Dolly Pull Test (Ref 18), using a PAT AT101E/20kN Adhesion Tester from DFD Instruments. A minimum of three samples per system (coating/substrate alloy) were tested. The adhesive used was Araldite 2021. Coated samples approximately $3 \mathrm{~cm} \times 3 \mathrm{~cm}$ were sections from a coated panel. Samples were ultrasonically cleaned in acetone, and a $25-\mathrm{mm}$ diameter dolly was then glued to the coated surface of the sample and allowed to cure for $12 \mathrm{~h}$. The coupling connector from the actuator was then attached to the dolly. Pressure was applied, which then was slowly increased to the actuator within the system until the dolly detached from the sample. The type of detachment (cohesive, or adhesive) and the load at failure were noted. Samples of both alloys and both coating powders were tested.

Microhardness testing was performed on the coated samples of both substrate alloys. Both in-plane, $H_{\mathrm{IP}}$ (parallel to the direction of coating growth) and out-of-plane,
$H_{\mathrm{OP}}$ (normal to the direction of coating growth) microhardness measurements were performed. $H_{\mathrm{IP}}$ measurements were performed on csa samples of the coated samples using a Buehler Micromet II microhardness indenter at a load of $0.3 \mathrm{~kg}$. $H_{\mathrm{OP}}$ measurements, also referred to as composite hardness (Ref 19), were performed using a MicroMaterials Nanotest system. In order to determine representative average values for the mechanical properties, 15 tests were performed on each uncoated/coated system. In the test, the load was increased in steps until a nominal load of $5000 \mathrm{mN}$ was reached. Two creep periods of $30 \mathrm{~s}$ were performed during the tests: at maximum load and at the $10 \%$ of the lowest load, during unloading. Corrections of the geometrical defects in the tip of the Berkovich indenter, thermal drift of the equipment, and uncertainty of the initial contact were also performed. Depth-sensing indentation measurements were used to determine the reduced, or composite, Elastic Modulus $\left(E_{\mathrm{r}}\right)$.

Surface roughness $\left(R_{\mathrm{a}}\right)$ of the coated panels was measured on a Diavite Surface Profiler, and signal analysis was performed using the Asmeto Ag Diasoft software (standard version 3.20). Evaluation length was $15 \mathrm{~mm}$ for all measurements, and five samples per system (coating/substrate alloy) were tested. Coated samples were placed on a flat surface, and the profiler tip was applied to a suitable area. The profiler was then automatically moved along the surface for the specified distance, and the collected data were transferred directly to an attached PC, as per ISO 4287. Analysis of the data was then performed, and key properties were quantified.

Coefficient of Friction $(\mu)$ dry friction tests were performed using a TE 67 pin-on-disk machine, operating in a reciprocating pin-on-flat geometry, under $5 \mathrm{~N}$ load for $60 \mathrm{~min}$, as per ASTM F 732. The ball was an AISI 5120 grade ball bearing. three samples per system (coating/ substrate alloy) were tested.

Pin-on-Disc wear analysis was performed on a TE 67 pin-on-disk machine, operating in a reciprocating pinon-flat geometry. Samples were subjected to a $5 \mathrm{~N}$ load at $0.02 \mathrm{~m} / \mathrm{s}$ over a sliding distance of $60 \mathrm{~m}$. The ball was an AISI 5120 grade ball bearing. Analysis of the results was based on Archard's equation (Ref 20) (Eq 2)

$k=V / F S$

where, $F$ is the normal load $(\mathrm{N}), S$ is the sliding distance (m), $V$ is the total wear volume $\left(\mathrm{mm}^{3}\right)$, and $k$ is the wear coefficient $\left(\mathrm{mm}^{3} /(\mathrm{N} \mathrm{m})\right)$. A minimum of three samples per system (coating/substrate alloy) were tested.

Taber Abrasion Wear resistance (ISO EN 438-2) was estimated from weight loss measurements under Taber 
Abrasive Wear. Samples $100 \mathrm{~mm} \times 100 \mathrm{~mm}$ were machined and coated. 2 Calibrase CS10 abrasive wheels were used on a Single Model Circular Taber Abraser (5135) with an $\mathrm{Al}_{2} \mathrm{O}_{3}$ abrader/rubber binder; $50 \mathrm{~mm}$ diam., $\mathrm{Al}_{2} \mathrm{O}_{3}=165 \mu \mathrm{m}, R_{\mathrm{a}}=40 \mu \mathrm{m}$. Loads of 2.5 and $5.0 \mathrm{~N}$ per wheel were applied, and specimens were rotated at $60 \mathrm{revs} / \mathrm{min}$ under the abrasive wheels. During the tests, room temperature was in the range of $20^{\circ} \mathrm{C}$ and $25^{\circ} \mathrm{C}$ and humidity was between 55 and $70 \%$. Wear was characterized gravimetrically by weighing the specimens after 100 , 200, 300, 400, 500, 1000, 2000, 3000, 4000, 5000 and every further 5000 revolutions. Panels $10 \mathrm{~cm} \times 10 \mathrm{~cm}$ of each alloy were prepared and the surface was ground to a 1200 grit finish. Coatings were then applied to the prepared panels. Each panel was ultrasonically cleaned in acetone prior to weighing. Tests were stopped once the substrate was exposed or after a maximum of 10,000 revolutions (10 cycles). The Taber wear index, TWI (the weight loss in $\mathrm{mg}$ per cycle (1000 revolutions) of abrasive wear), was calculated from the expression:

$\mathrm{TWI}=\left(W_{\mathrm{b}}-W_{\mathrm{a}}\right) / N$

where $W_{\mathrm{a}}$ and $W_{\mathrm{b}}$ are the specimen weights, in mg, after and before the test, respectively, and $N$ is the number of cycles (revolutions/1000). Low values of TWI indicate relatively good abrasion resistance. A minimum of three samples per system (coating/substrate alloy) were tested.

Microabrasion testing was performed on a Plint TE66 microabrasion tester (Fig. 1) and was used to measure the effect of rolling contact between an AISI 52100 ball bearing $(R=13.5 \mathrm{~mm})$ and the surface of the thermal spray coating. To promote three-body microabrasion wear in the contact area, a $\mathrm{SiC}$ powder, with a nominal particle size of 8-10 $\mu \mathrm{m}$, was mixed with distilled water to produce the slurry. The resultant wear scar (crater) was measured using a Zeiss Supra 35VP Variable Pressure Field Emission Scanning Electron Microscope (FESEM). The geometry of the wear scar was assumed to reproduce the spherical geometry of the ball, and the wear volume $(\Delta V)$ may be calculated by measurement of either the crater diameter $(b)$ or its depth $(h)$, based on the radius of the ball $(R)$. These calculations are based on the formulae published by Stack et al. (Ref 21).

For $b \ll R: \Delta V=\pi b^{4} / 64 R$

For $h \ll R: \Delta V=\pi h^{2} R$

$\mathrm{SiC}$ powder slurry blends were based on a SiC:Water ratio of $0.025 \mathrm{~g} \mathrm{SiC} / \mathrm{ml} \mathrm{H}_{2} \mathrm{O}$. Three loads were applied : 1 , 3 , and $5 \mathrm{~N}$ and each experiment was performed for 2500 revolutions, equivalent to a sliding distance of $212 \mathrm{~m}$, with a slurry flow rate of $100 \mu \mathrm{L} / \mathrm{min}$. A minimum of three samples per system (coating/substrate alloy) were tested.

\section{Results and Discussion}

Microstructural analysis was performed on samples of each coating/substrate system. As can be seen in Fig. 2 the f625 coatings had relatively low porosity and had excellent apparent adhesion with the substrate material. Since these coatings were not fused (flame- or laser-remelting), high levels of particle oxidation and porosity were expected in the microsections. However, in the samples viewed, this was not the case which suggested that the incorporation of argon during deposition reduced the interaction between oxygen and the molten in-flight particles. In addition, coating thickness variations were low, implying the achievement of good quality coatings.

In contrast, the fWC/Co coatings had high levels of porosity with separation of the $\mathrm{WC}$ and Co phases. It has been suggested that the Co-phase is an amorphous phase comprising W, C, Co, and oxygen (Ref 22). The development of this phase, along with extensive porosity, undermines the integrity of the coating and can increase susceptibility to wear degradation. However, the highvolume presence of WC particles at the surface would suggest that the surface hardness would be high, based on the high measured hardness values of these WC/Co particles (Table 3). However, phase separation in these

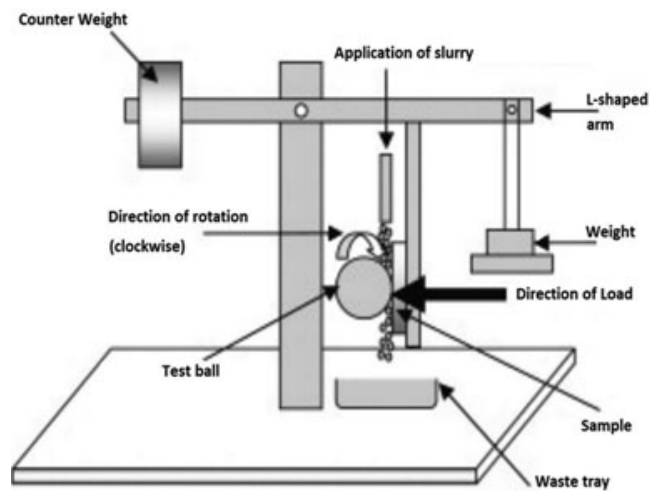

(a)

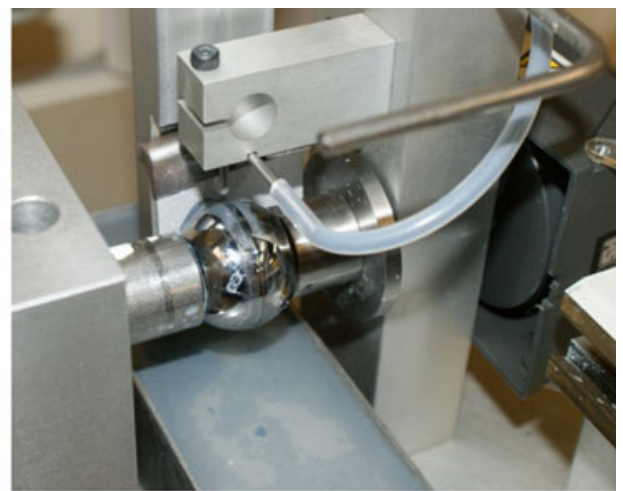

(b)

Fig. 1 Plint TE66 Micro-Abrasion Test Rig (a) schematic (b) photograph 
coatings results in high surface roughness, which would reduce the effective contact area in wear environments, particularly at lower loads.

Surface hardness has been strongly linked to superior wear properties, while some authors have found a linear relationship between wear and a hardness/Elastic Modulus ratio (Ref 23, 24). As can be seen, there are substantial differences between the in-plane $\left(H_{\mathrm{IP}}\right)$ and out-of-plane $\left(H_{\mathrm{OP}}\right)$ hardness results. These were possibly related to reduced intersplat cohesive strengths, caused by the

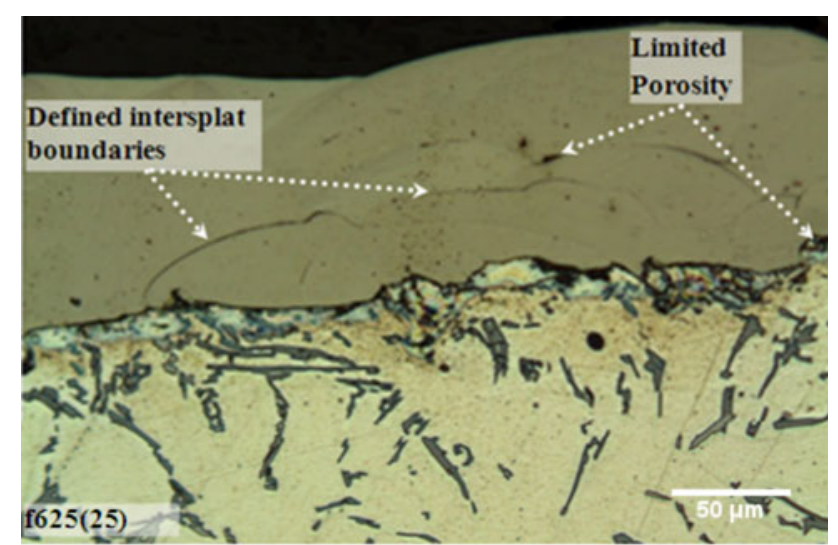

(a)

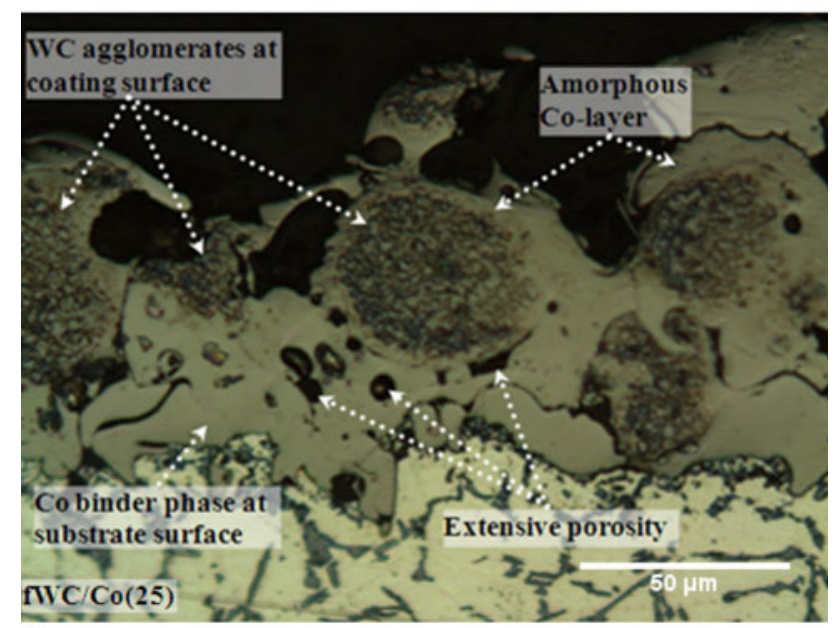

(b)

Fig. 2 Typical microstructures of the homogeneous f625 coating and biphasic fWC/Co coatings effects of high-porosity levels, defined intersplat boundary regions, in-flight oxidation, and low coating thickness which, for these coatings, was generally $<100 \mu \mathrm{m}$. While the low-porosity (f625) coatings differ in $H_{\mathrm{IP}} / H_{\mathrm{OP}}$ hardness by a factor of 3 , the higher-porosity ( $\mathrm{fWC} / \mathrm{Co}$ ) coatings differ by a factor of 10-20. The anisotropy in the f625 coatings was most likely due to porosity and the lamellar structure of the coating (Ref 25). The high-porosity levels in the fWC/Co coatings may account for this anisotropy (Eq 1). High $R_{\mathrm{a}}$ values, although reducing the contact area between contra-surfaces, can lead to an increased chance of transition from two-body to three-body wear (Ref 26), even at higher loads. As a result of the increased hardness and surface roughness of the coatings, both coatings indicated friction coefficients approximately 67\% lower than the uncoated alloys $\left(\mu_{\mathrm{LM} 24}=0.69, \mu_{\mathrm{LM} 25}=0.79\right)$.

The properties of the f625 coating compare well with published results. Various authors have reported hardness values of $5.98 \mathrm{GPa}$ (Ref 27) (on mild steel) and 11.77 GPa (on AISI 1015 mild steel) for FS NiCrBSi coatings. Serres et al. (Ref 28) reported $H_{\mathrm{IP}}$ hardness values of $10.08 \pm 0.72 \mathrm{GPa}$, and $E_{\mathrm{r}}$ values of $119.89 \mathrm{GPa}$ for NiCrBSi coatings applied to C38 steel using a hybrid APS system (APS + in situ laser remelting). González et al. (Ref 29) reported hardness values of $8.83 \mathrm{GPa}$, which are lower than the values presented here. However, the surface roughness $\left(R_{\mathrm{a}}\right)$ of the fused coatings was very low $(0.44 \mu \mathrm{m})$. This is probably due to a reduction in the presence of phases such as dendritic/interdendritic Ni-phases and Cr-particles, which have been shown to increase the hardness and wear resistance of these coatings (Ref 30). Higher coating hardness has been associated with the as-deposited microstructure of these coatings, because of the presence of unmelted particles. Bergant et al. (Ref 31) reported that increases in coating adhesion could be achieved by heat treatments at high temperature, though this was dependent on the substrate material as $1080{ }^{\circ} \mathrm{C}$ was reported as being the minimum effective temperature. A higher coating hardness would be expected since no post-deposition fusing of the f625 coating was performed, because of the low thermal stability of Al-alloys and related concerns with regard to sample deformation.

The deposited fWC/Co coatings were very porous and had a biphasic structure. This resulted in the development of a hard WC layer at the surface which interfered with the development of the coating thickness. As a result,

Table 3 Tabulated results for the mechanical testing of the coated and uncoated samples

\begin{tabular}{|c|c|c|c|c|c|c|c|c|}
\hline \multirow[b]{2}{*}{ Coating } & \multirow[b]{2}{*}{ Alloy } & \multicolumn{2}{|c|}{ Microhardness, GPa } & \multirow[b]{2}{*}{$E_{\mathbf{r}}, \mathbf{G P a}$} & \multirow[b]{2}{*}{$\mu$} & \multirow[b]{2}{*}{$R_{\mathrm{a}}, \mu \mathrm{m}$} & \multirow[b]{2}{*}{ Coating thickness, $\mu \mathrm{m}$} & \multirow[b]{2}{*}{ Porosity, \% } \\
\hline & & $\boldsymbol{H}_{\mathbf{I P}}$ & $\boldsymbol{H}_{\mathbf{O P}}$ & & & & & \\
\hline \multirow[t]{2}{*}{$f 625$} & LM24 & $3.32^{ \pm 0.05}$ & $9.76^{ \pm 0.57}$ & $57.02^{ \pm 1.71}$ & 0.33 & 8.18 & $80.2^{ \pm 3.2}$ & $4.55^{ \pm 0.7}$ \\
\hline & LM25 & $4.37^{ \pm 0.06}$ & $10.25^{ \pm 0.75}$ & $80.84^{ \pm 15.36}$ & 0.12 & 8.31 & $81.7^{ \pm 2.8}$ & $3.38^{ \pm 0.5}$ \\
\hline \multirow[t]{2}{*}{ fWC/Co } & LM24 & $1.16^{ \pm 0.02}$ & $16.08^{ \pm 2.67}$ & $33.29^{ \pm 3.66}$ & 0.30 & 11.13 & $98.9^{ \pm 19.9}$ & $9.08^{ \pm 1.2}$ \\
\hline & LM25 & $1.35^{ \pm 0.01}$ & $16.78^{ \pm 2.03}$ & $42.77^{ \pm 1.71}$ & 0.29 & 11.43 & $99.7^{ \pm 10.9}$ & $7.39^{ \pm 1.1}$ \\
\hline
\end{tabular}


although high $H_{\mathrm{OP}}$ values are quoted, the low ratio between $H_{\mathrm{IP}}$ and $H_{\mathrm{OP}}$, combined with low coating density, suggested that these coatings would perform poorly in wear testing particularly in the presence of adhesive wear. The high $H_{\mathrm{OP}}$ values were related to the morphology of the deposited coatings, with predominantly harder WC particles at the surface and the softer amorphous Cophase at the substrate interface. The resultant properties would suggest that in the presence of predominantly twobody wear, these coatings would experience very low wear rates. Similar $H_{\mathrm{OP}}$ values have been quoted for $\mathrm{WC} / \mathrm{Co}$ coatings applied with other thermal spray processes, though no equivalent recent reports could be found for FS WC/Co coatings. In addition, the estimated moduli $\left(E_{\mathrm{r}}\right)$ for these coatings (33-43 GPa) were much lower than those reported for HVOF-applied WC/12Co coatings $(268 \mathrm{GPa})$, albeit with much lower-porosity levels $(0.2 \%)$ (Ref 32). Therefore, the biphasic nature of these deposited coatings combined with the high-porosity levels suggest that high wear rates would result from exposure to aggressive (three-body and adhesive) wear environments.

Taber Abrasion results, shown in Fig. 3, indicated that there was a strong link between coating integrity and wear rate. As a result, the f625 coatings displayed much lower wear rates than the fWC/Co coatings. In addition, there appeared to be a two-tier wear relationship between the TWI and Cycles. Initially (TWI $<1$ cycle), the process was assumed to be a combination of adhesive wear and two-/three-body abrasive wear, producing high wear rates (Ref 23). However, the wear rate of the f625 coatings were less affected by this transition than the fWC/Co coatings. This combined wear was most likely associated with the rubber-binder phase of the Calibrase wheels used in the test which may have adhered to the surface of the coating, causing shearing of the surface particles. In addition, $\mathrm{Al}_{2} \mathrm{O}_{3}$ particles were simultaneously released from the wheels into the contact area. The increased wear of the

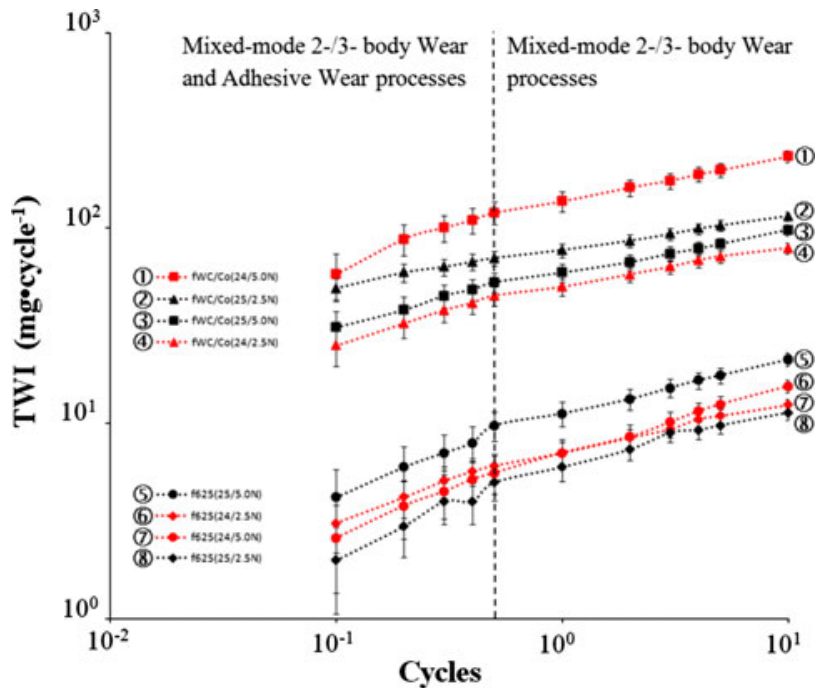

Fig. 3 Taber Abrasion results for the FS coatings on LM24 and LM25 at 2.5 and 5.0 N. Note: Error Bars were calculated as \pm 1 standard deviation two-phase fWC/Co coatings is, therefore, reflective of the increased size of the solid, predominantly WC, particles at the surface of these coatings (Fig. 4), in interaction with the materials of the CS10 wheels. Bonache et al. (Ref 33) attributed this degradation to coating spallation caused by subsurface cracking (Ref 33) which resulted in the pull-out of the WC-phase, exposing the softer amorphous Co-phase and leading to high initial wear rates. Similar effects were reported by Gee et al. (Ref 34). The superior wear performance of the f625 coatings, on both substrates and at both loads, is related to the more mechanically homogeneous structure of these coatings (Fig. 5). This produced good intersplat cohesive bonding and resulted in a higher Elastic Modulus, combined with lower-porosity levels and a reduced $H_{\mathrm{IP}} / H_{\mathrm{OP}}$ ratio. In addition, the dominant wear process of the fWC/Co coatings was threebody wear, while adhesive wear seemed to dominate wear mechanisms in the NiCrBSi coatings. As TWI approached one cycle, the wear rates reduced dramatically, and it is suggested that the wear process for both coatings became predominantly a two-/three-body wear process, dominated by three-body wear.

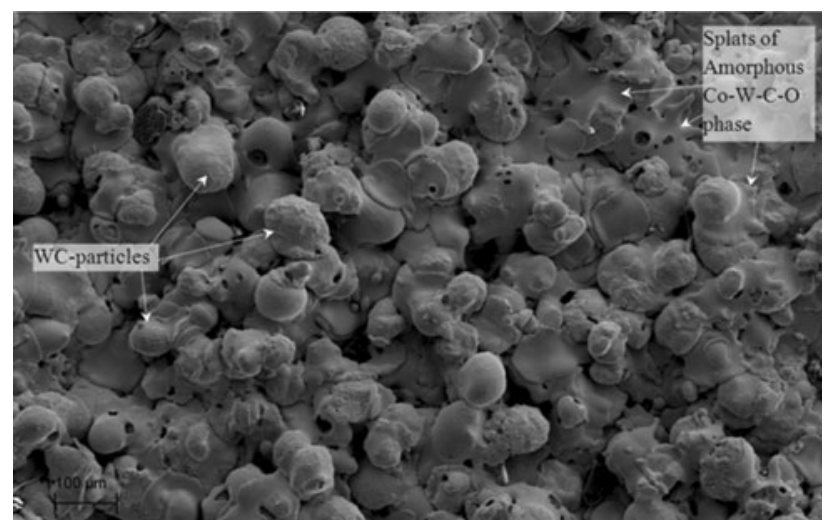

Fig. 4 SEM image of a typical $\mathrm{fWC} / \mathrm{Co}$ coating, showing the amorphous $\mathrm{Co}-\mathrm{W}-\mathrm{C}-\mathrm{O}$ splats and the hard $\mathrm{WC} / \mathrm{Co}$ particles

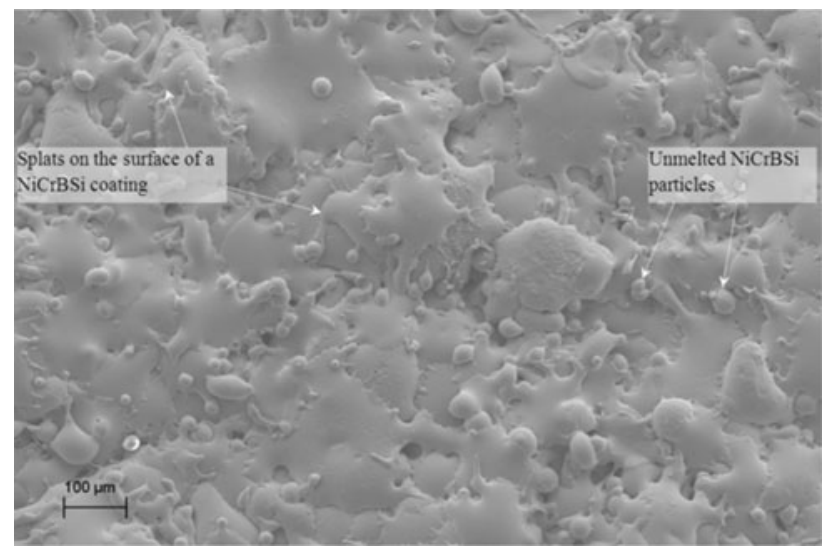

Fig. 5 SEM image of a typical f625 coating, showing the surface splat structures and unmelted particles 


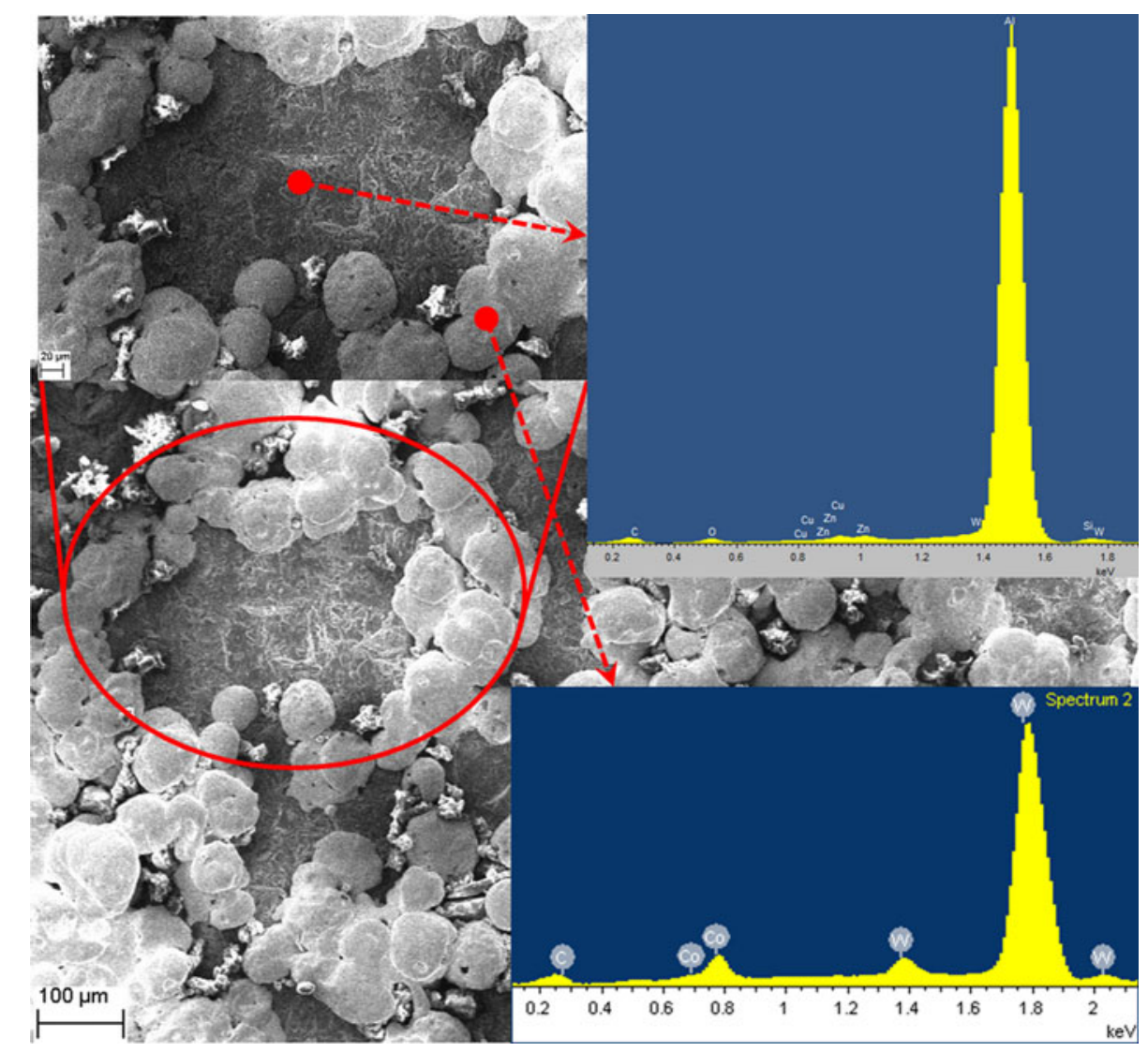

Fig. 6 SEM photomicrograph and EDS (inset) of wear region of fWC/Co on LM24, showing removal of the coating from the surface with only the base substrate (LM24) remaining in parts of the wear track

As discussed earlier, the integrity of the deposited coating is strongly dependent on the mechanical properties of both the coating and substrate materials. Evidence of this can be seen in Fig. 3. At the lower load (2.5 N), wear rates of the fWC/Co (24) systems were superior to the $\mathrm{fWC} / \mathrm{Co}(25)$ systems. However, increasing the load to $5.0 \mathrm{~N}$ caused a dramatic increase in the wear of the $\mathrm{fWC} /$ $\mathrm{Co}(24)$ systems and reduced the wear of the $\mathrm{fWC} / \mathrm{Co}(25)$ systems. Therefore, at higher loads $(5 \mathrm{~N}), \mathrm{WC}$ and $\mathrm{SiC}$ particle re-embedding is likely to be more predominant in coatings on the LM25 substrate, resulting in increased wear resistance (Fig. 6,7). However, for the f625 coatings, the softer LM25 substrate resulted in higher wear rates at the higher loads, whereas the wear rates for the harder LM24 were very similar for both loads. This suggested that the coating material controlled the wear process for these systems (Fig. 8). Reported TWI values (Ref 35) for similar coatings are much lower than those reported here. However, these tests were performed with $\mathrm{H}-22$ wheels, which provide a purely abrasive test environment. For the tests reported here, the values ranged between $11.4 \mathrm{mg} / \mathrm{cycle}$ (f625(25)@2.5 N) and 232.3 mg/cycle (fWC/Co(24) @ $5.0 \mathrm{~N}$ ). These indices again suggest a potentially definable relationship between the interaction of the coating and the substrate and the resultant wear properties. In general, it may be surmised that for cermet coating materials, an inverse wear rate relationship exists with the substrate hardness and the applied load, while for metallic coating materials, wear increases as the load increases and the substrate hardness decreases. However, further investigation would be required to properly quantify this relationship.

Recent studies on the transition between low-wear (two-body) and high-wear (three-body) processes have begun to focus on the mechanisms occurring at the microlevel, particularly on thin coatings (Ref 36, 37). Studies by Adachi et al. (Ref 38) and Stack et al. (Ref 39-41) looked at the development of, and transition between, two- and three-body microabrasion processes, in various material/environmental conditions. In general, it was found that although the dominating microabrasion process was three-body wear, slurry starvation at increased loads could also lead to two-body wear. At low loads $(\leq 1 \mathrm{~N})$, it was shown that mixed-model two-/three-body wear regimes predominated, while at higher test loads $(>1 \mathrm{~N})$, the wear volumes reduced as wear processes tended to transition to ridge formation and a pure two-body (rolling) process, associated with the hardness of the wear interface. This relationship between hardness and microabrasion wear processes is important when considering surface treatments, as higher hardness coatings should lead to reduced wear. However, it has also been shown that 


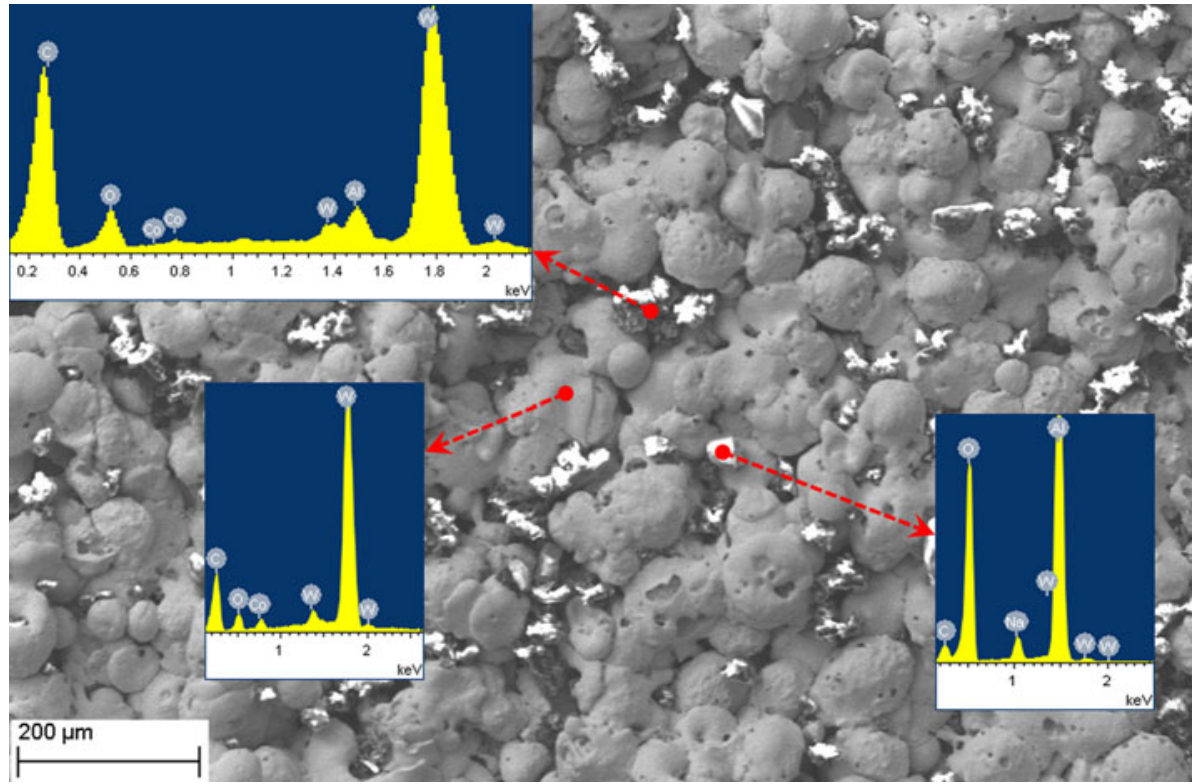

Fig. 7 SEM photomicrograph and EDS (inset) of surface of fWC/Co on LM25 showing debris comprising $\mathrm{Al}_{2} \mathrm{O}_{3}$ particles and crushed $\mathrm{Al}_{2} \mathrm{O}_{3}$ and $\mathrm{WC} / \mathrm{Co}$ particles. The alumina $\left(\mathrm{Al}_{2} \mathrm{O}_{3}\right)$ most probably originates from the abrasive medium present in the Taber wheel

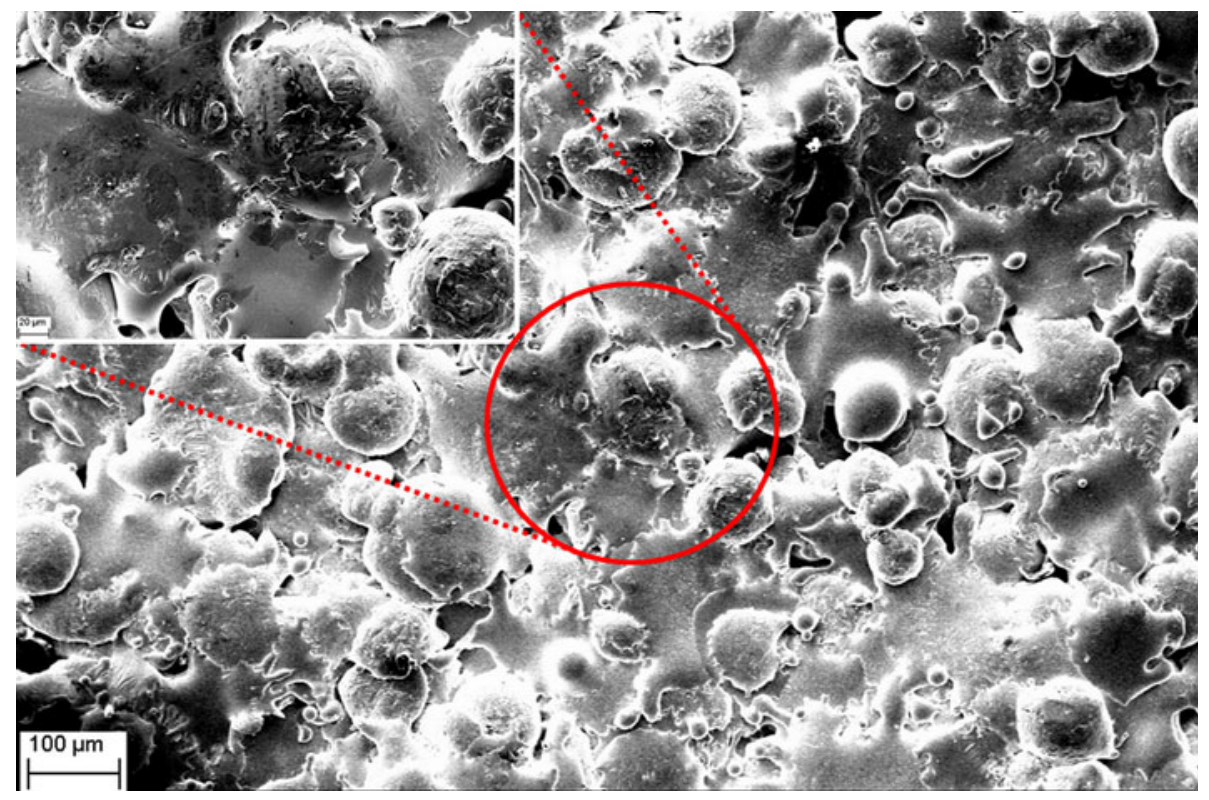

Fig. 8 SEM photomicrographs of f625 on LM24 (identical in morphology to f625 on LM25) which suggest that this coating tended to degrade through abrasive wear during the final stages of the Taber Abrasion test. No substrate was apparent in the wear track

coarser carbides perform better than finer carbides in microabrasion (Ref 42, 43). The proposed process suggests that in microabrasion, the binder phase is removed preferentially, followed by carbide grain pull-out. By corollary, coarser WC grains are more difficult to pull-out which leads to an improvement in the wear resistance of these coatings. From the microabrasion results shown in Fig. 8, a similar process may occur as none of the tested
fWC/Co coatings indicated any wear scar at the end of testing.

From the limited data published on the effect of microabrasion on metallic and cermet thermal spray coatings, the general trend seems to be a increase in wear volume with increasing load $(>3 \mathrm{~N})$ for sliding distances (Ref 40, 44). In the results presented (Fig. 6), however, this was not the case for the f625 coatings, as an increase in 


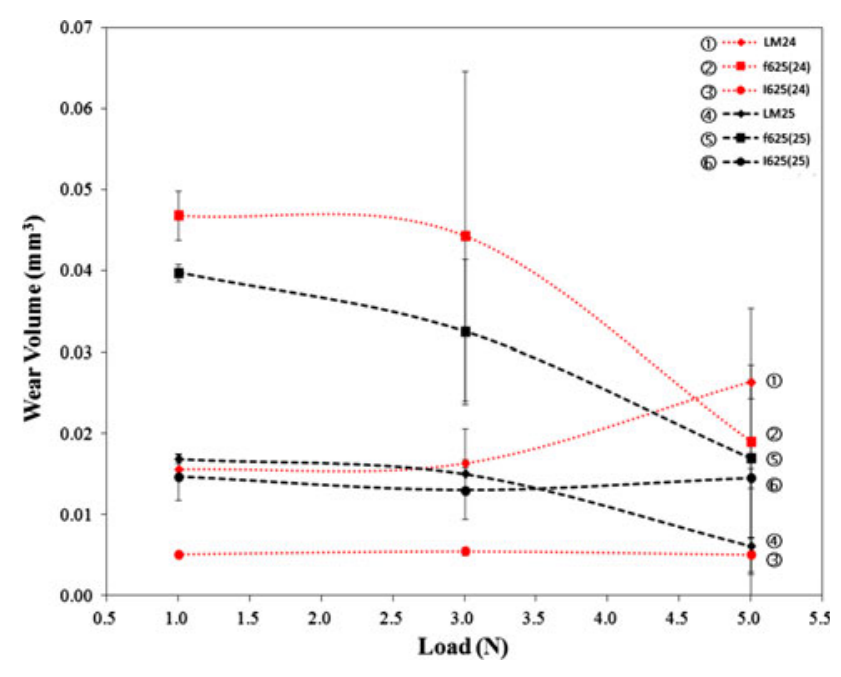

Fig. 9 Plot of Load vs. Microabrasion Wear Volume, with Error Bars, for coated and uncoated LM24 and LM25 samples. Note: Error Bars were calculated as \pm 1 standard deviation

load caused a decrease in wear rate. It has been suggested that the wear process in these coatings is in some way related to fatigue at the intersplat boundaries and at the pores. A strong relationship between coating durability (fatigue) and porosity has been cited by other authors (Ref 45, 46). Therefore, in coatings, such as f625, fatigue would be expected to be more predominant under low loads than at the higher, compressive, loads. HVOFapplied Inconel 625 results (I625) are provided for comparative purposes. The mechanical properties of the Inconel 625 coating material would be similar to those of the NiCrBSi coating material. As a result, it can be conjectured that the superior performance of the HVOF coatings can be related to the improved microstructural properties of these coatings, with reduced porosity and in-flight oxidation, and improved intersplat cohesive strengths. However, it is interesting to note that, as the load increases, the performance of both the f625 and I625 coatings approach similar wear rates. This strongly suggests that two-body wear degradation is defined by the material properties rather than anomalies in the deposition process (Fig. 9).

As observed with the Taber Abrasion results, a notable difference was identified between the two substrate alloys in the microabrasion testing. As can be seen, the performance of the coating was strongly dependent on the properties of the substrate. At lower loads $(<3 \mathrm{~N})$, the coatings on the LM24 (high hardness/high Cu-content) samples had lower resistance to microabrasive wear than the coatings applied to the LM25 (low hardness/low Cucontent) substrate. If this was related to intersplat fatigue degradation (Ref 14), then it would suggest that during coating build-up on the harder LM24 substrate, material rebounding from the surface interfered with the deposition of subsequent splats while also increasing the temperature differential between the deposited splats and the depositing splats. This would have a significant effect on the intersplat cohesive strengths, though it would not
Table 4 Pin-on-disk analysis giving average Wear Coefficients for the uncoated and coated substrates

\begin{tabular}{lll}
\hline & \multicolumn{2}{c}{$\begin{array}{c}\text { Wear coefficient, } \mathbf{~}, \mathbf{~ m m}^{\mathbf{3}}, \\
{[\mathbf{N ~ m}]^{-\mathbf{1}} \times \mathbf{1 0}^{-\mathbf{8}}}\end{array}$} \\
\cline { 2 - 3 } Coating & $\mathbf{L M 2 4}$ & $\mathbf{L M 2 5}$ \\
\hline$\ldots$ & 5110 & 50,200 \\
f625 & 3.09 & 3.23 \\
fWC/Co & 0.26 & 0.26 \\
\hline
\end{tabular}

necessarily increase the porosity levels of the coating. Detection of these anomalies would require more intricate microstructural analysis, which was not performed in this investigation, but is recommended for future study. At loads in excess of $3 \mathrm{~N}$, the wear performances of the NiCrBSi coatings were similar on both alloys, suggesting a transition to predominantly two-body abrasive wear.

For the uncoated samples, it has been suggested (Ref 21) that the LM25 was subjected to greater workhardening during the testing, which resulted in lower wear rates at the higher loads $(>3 \mathrm{~N})$. This work-hardening, along with the potential embedding of the abrasive $\mathrm{SiC}$ microparticles, could account for the improved performance of the softer LM25 alloy over the harder LM24 alloy.

The results of the pin-on-disk analysis are given in Table 4, which compare well with published results (Ref $47,48)$. The superior performance of the FS coatings on both the LM24 and LM25 substrates was evident, with an average improvement of 3-5 orders of magnitude over the uncoated substrates. However, unlike the results of the Taber Abrasion tests, the fWC/Co coatings indicated superior performance to the f625 coatings. It is surmised that the smaller contact area of the pin, combined with the re-embedding of the hard $\mathrm{WC} / \mathrm{Co}$ particles into the amorphous Co-phase, provided increased wear resistance. Unlike the Taber Abrasion and microabrasion results, however, no substrate-dependency was noted for any of the coatings.

\section{Conclusions}

FS coatings were successfully applied to two cast automotive aluminum alloys (LM24 and LM25), with high hardness (high $\mathrm{Cu}$ content, LM24) and low hardness (low $\mathrm{Cu}$ content, LM25). Coating integrity and performance in wear testing was strongly dependent on the substrate alloy and the interaction between the substrate and the coating.

The microstructural integrity of the homogeneous NiCrBSi coating was improved by incorporating argon as a tertiary gas in the FS process. However, homogeneous WC/Co coatings could not be developed on either substrate. As a result, the NiCrBSi coatings were found to have lower porosity and lower surface roughness values than the biphasic structure of the WC/Co coatings.

The FS coatings properties indicated a material- and property-specific dependency on the substrate material. 
The results suggested that, as the coating hardness $\left(H_{\mathrm{c}}\right)$ increased, the effect on the Young's Modulus decreased. For the f625 coating, with a $H_{\mathrm{c}}$ of $\sim 10 \mathrm{GPa}, E_{\mathrm{r}}(24)$ was approximately $25 \%$ lower than $E_{\mathrm{r}}(25)$, whereas for the fWC/Co coating, with a $H_{\mathrm{c}}$ of $\sim 16 \mathrm{GPa}$, the $E_{\mathrm{r}}$ values were much closer in value. This was related to the porosity levels, which were slightly higher for coatings on the LM24 substrate. Coating bond strengths were all greater than $10 \mathrm{MPa}$, and all failures occurred adhesively because of decohesion. However, Surface Roughness $\left(R_{\mathrm{a}}\right)$ measurements for these coatings indicated no dependency on the substrate.

High hardness coatings applied to the high hardness (LM24) substrate resulted in reduced performance in combined adhesive/abrasive test environments. However, improved performances for these systems were noted in purely abrasive wear tests-microabrasion and pin-on-disk. It was found that the wear rates in the pin-on-disk tests were extremely low. For the microabrasion testing, no wear scar could be detected on the tested surface. This resistance-to-abrasive wear degradation was attributed to the high-hardness surface of these coatings.

NiCrBSi coatings had lower hardness than the WC/Co coatings and performed well in combined adhesive/abrasive wear conditions. This was related to the homogeneity of the NiCrBSi coatings resulting in greater intersplat cohesive strength.

In two- and three-body microabrasion wear conditions, the performance of the coating was strongly dependent on the substrate material, particularly at lower loads. Wear of the $\mathrm{NiCrBSi}$ coatings were high for loads up to $3 \mathrm{~N}$. This was attributed to intersplat fatigue degradation. However, above $3 \mathrm{~N}$, wear of these coatings decreased dramatically and approached the wear rates of HVOF-applied Inconel 625 coatings. The low-hardness LM25 alloy underwent embedding of the $\mathrm{SiC}$ wear particles and microhardening effects, which resulted in a reduction in wear as the load increased. Wear of the harder LM24 alloy increased with increasing load, implying that the transition from three- to two-body abrasive wear above a load of $3 \mathrm{~N}$ did not occur on these alloys.

Pin-on-disk wear results were independent of the substrate alloy, and substantial improvements, by a factor of $10^{2}-10^{4}$, were achieved with the coated samples.

The harder LM24 sample most closely approximated Archard's equation for wear degradation. The softer LM25 substrate did not because of embedding of SiC particles into the contact area, interfering with the natural wear processes of this material. The coated samples also did not wear according to Archard's equation because of wear transitions between two- and three-body wear, adhesive wear and intersplat cohesive failures.

In general,, these results suggested that harder coatings perform exceptionally well in predominantly abrasive wear conditions but highlight a potential problem for these coatings in pure adhesive or combined adhesive/ abrasive wear conditions.

\section{Acknowledgments}

The authors would like to thank Enterprise Ireland and the Dublin Institute of Technology for the opportunity to perform this study. In addition, the authors would like to thank the following persons for their assistance in this study: Prof. J. Gomes, Dept. de Engenharia Mecânica, Campus de Azurém, 4800-058 Guimarães, Portugal; Dr. E. Mihaylova, Centre for Industrial and Engineering Optics, Dublin Institute of Technology, Ireland; and Dr. S. Jerrams, Centre for Elastomer Research, Dublin Institute of Technology, Ireland.

\section{References}

1. M. Schwartz, Innovations in Materials Manufacturing, Fabrication, and Environmental Safety ${ }^{(}$, CRC Press, Boca Raton, 2011, p 385-444

2. G. Bolelli, Replacement of Hard Chromium Plating by Thermal Spraying-Problems, Solutions and Possible Future Approaches, Surf. Eng., 2009, 25, p 263-269

3. T. Sahraoui, S. Guessasma, N.E. Fenineche, G. Montavon, and C. Coddet, Friction and Wear Behaviour Prediction of HVOF Coatings and Electroplated Hard Chromium Using Neural Computation, Mater. Lett., 2004, 58, p 654-660

4. O.K. Legg, Hard-Chrome Coatings: Advanced Technology for Waste Elimination Final Report, 1997

5. N. Krishnan, A. Vardelle, and J.G. Legoux, A Life Cycle Comparison of Hard Chrome and Thermal Sprayed Coatings: A Case Example of Aircraft Landing Gears, Proc. Thermal Spray 2008: Crossing Borders, 2008, p 212-216

6. S. Kuroda, M. Watanabe, K. Kim, and H. Katanoda, Current Status and Future Prospects of Warm Spray Technology, J. Thermal Spray Technol., 2011, 20, p 653-676

7. S. Ji, Q. Gu, and B. Xia, Porosity Dependence of Mechanical Properties of Solid Materials, J. Mater. Sci., 2006, 41, p 1757-1768

8. N. Kobayashi, K. Iwamoto, Y. Miyazaki, K. Toyama, K. Tanaka, N. Suzuki, and T. Toyota, Young's Moduli and Wear of Cermet Coatings, Proc. IMechE J., 2009, 223, p 437-443

9. P. Fauchais, G. Montavon, R.S. Lima, and B.R. Marple, Engineering a New Class of Nano-based Microstructures from Agglomerated Nanostructured Particles, Suspensions and Solutions: An Invited Review, J. Phys. D, 2011, 44, p 1-53

10. R. McPherson, A Review of Microstructure and Properties of Plasma Sprayed Ceramic Coatings, Surf. Coat. Technol., 1989, 3940, p 173-180

11. J. Rösler, M. Bäker, and M. Volgmann, Stress State and Failure Mechanisms of Thermal Barrier Coatings: Role of Creep in Thermally Grown Oxide, Acta Mater., 2001, 49, p 3659-3670

12. N. Serres, N. Portha, and F. Machi, Influence of Salt Fog Aging Tests on Mechanical Resistance of Laser Clad-Coatings, Surf. Coat. Technol., 2011, 205, p 5330-5337

13. D. Culliton, A. Betts, D. Kennedy, Impact of Intermetallic Precipitates on the Tribological and/or Corrosion Performance of Cast Aluminium Alloys: A Short Review, Int. J. Cast Metals (unpublished results)

14. H.J. Kim, Y.G. Kweon, and R.W. Chang, Wear and Erosion Behaviour of Plasma-Sprayed WC-Co Coatings, J. Therm. Spray Technol., 1994, 3, p 169-178

15. R.S. Lima, A. Kucuk, and C.C. Berndt, Evaluation of Microhardness and Elastic Modulus of Thermally Sprayed Nanostructured Zirconia Coatings, Surf. Coat. Technol., 2001, 135, p 166172

16. S. Tobe, A Review on Protection from Corrosion, Oxidation and Hot Corrosion by Thermal Spray Coatings, Proc. ITSC, 1998, 15, p 3-11

17. V. Pershin, J. Mostaghimi, S. Chandra, and T. Coyle, A Gas Shroud Nozzle for HVOF Spray Deposition, Proc. ITSC, 1998, 15, p 1305-1308

18. ASTM D4541-09e1 Standard Test Method for Pull-Off Strength of Coatings Using Portable Adhesion Testers

19. D. Beegan and M.T. Laugier, Application of Composite Hardness Models to Copper Thin Film Hardness Measurement, Surf. Coat. Technol., 2005, 199, p 32-37 
20. J.F. Archard, Contact and Rubbing of Flat Surfaces, J. Appl. Phys., 1953, 24, p 981-988

21. M.M. Stack and M. Mathew, Micro-abrasion Transitions of Metallic Materials, Wear, 2003, 255, p 14-22

22. P.S. Babua, B. Basu, and G. Sundararajan, Processing-StructureProperty Correlation and Decarburisation Phenomenon in Detonation Sprayed WC-12Co Coatings, Acta Mater., 2008, 56, p 5012-5026

23. W. Ni, Y.-T. Cheng, M.J. Lukitsch, A.M. Weiner, L.C. Lev, and D.S. Grummon, Effects of the Ratio of Hardness to Young's Modulus on the Friction and Wear Behavior of Bilayer Coatings, Appl. Phys. Lett., 2004, 85, p 4028-4030

24. H.F. Gong, and T.M. Shao, Influence of Heat Treatment on Hardness, Elastic Modulus and Bonding Strength of Ti/Ta/TiN/ TaN Nanomultilayer Coatings, $A d v$. Tribol., 2010,3(IV), p 808-811

25. W. Tillmann, B. Klusemann, J. Nebel, and B. Svendsen, Analysis of the Mechanical Properties of an Arc-Sprayed WC-FeCSiMn Coating: Nanoindentation and Simulation, J. Thermal Spray Technol., 2011, 20, p 328-335

26. H.A. McKellop, P. Campbell, S.H. Park, T.P. Schmalzried, P. Grigoris, H.C. Amstutz, and A. Sarmiento, The Origin of Submicron Polyethylene Wear Debris in Total Hip Arthroplasty, Clin. Orthop., 1995, 311, p 3-20

27. M.P. Planche, H. Liao, B. Normand, and C. Coddet, Relationships Between NiCrBSi Particle Characteristics and Corresponding Coating Properties using Different Thermal Spraying Processes, Surf. Coat. Technol., 2005, 200, p 2465-2473

28. N. Serres, F. Hlawka, S. Costil, C. Langlade, and F. Machi, Microstructures and Mechanical Properties of Metallic NiCrBSi and Composite NiCrBSi-WC Layers Manufactured via Hybrid Plasma/Laser Process, Appl. Surf. Sci., 2011, 257, p 5132-5137

29. R. González, M. Cadenas, R. Fernández, J.L. Cortizo, and E. Rodríguez, Wear Behaviour of Flame Sprayed NiCrBSi Coating Remelted by Flame or by Laser, Wear, 2007, 262, p 301-307

30. T. Liyanage, G. Fisher, and A.P. Gerlich, Influence of Alloy Chemistry on Microstructure and Properties in NiCrBSi Overlay Coatings Deposited by Plasma Transferred Arc Welding (PTAW), Surf. Coat. Technol., 2010, 205, p 759-765

31. Z. Bergant and J. Grum, Quality Improvement of Flame Sprayed, Heat Treated, and Remelted NiCrBSi Coatings, J. Therm. Spray Technol., 2009, 18, p 380-391

32. Y.Y. Santana, P.O. Renault, M. Sebastiani, J.G. La Barbera, J. Lesage, E. Bemporad, E. Le Bourhis, E.S. Puchi-Cabrera, and M.H. Staia, Characterisation and Residual Stresses of WC-Co Thermally Sprayed Coatings, Surf. Coat. Technol., 2008, 202, p 4560-4565

33. V. Bonache, M.D. Salvador, J.C. García, E. Sánchez, and E. Bannier, Influence of Plasma Intensity on Wear and Erosion Resistance of Conventional and Nanometric WC-Co Coatings Deposited by APS, J. Thermal Spray Technol., 2011, 20, p 549-559
34. M.G. Gee, A. Gant, and B. Roebuck, Wear Mechanisms in Abrasion and Erosion of WC/Co and Related Hardmetals, Wear, 2007, 263, p 137-148

35. B. Wielage, T. Lampke, and T. Grund, Thermal Spraying of Wear and Corrosion Resistant Surfaces, Key Eng. Mater., 2008, 384, p 75-98

36. J.C.A. Batista, M.C. Joseph, C. Godoy, and A. Matthews, Microabrasion Wear Testing of PVD TiN Coatings on Untreated and Plasma Nitrided AISI, H13 Steel, Wear, 2002, 249, p 971-979

37. K. Bose and R.J.K. Bose, Influence of Load and Speed on Rolling Micro-abrasion of CVD Diamond and Other Hard Coatings, Diam. Relat. Mater., 2003, 12, p 753-756

38. K. Adachi and I.M. Hutchings, Wear-mode Mapping for the Micro-Scale Abrasion Test, Wear, 2003, 255, p 23-29

39. M.M. Stack et al., Mapping the Micro-abrasion Resistance of WC/Co Based Coatings in Aqueous Conditions, Surf. Coat. Technol., 2004, 183, p 337-346

40. M.M. Stack and M.T. Mathew, Transitions in Micro-abrasion Mechanisms for HVOF Coated Steels, Proc. IMechE J., 2005, 219 , p 49-57

41. M.M. Stack, J. Rodling, M.T. Mathew, H. Jawan, W. Huang, G. Park, and C. Hodg, Micro-abrasion-Corrosion of a $\mathrm{Co}-\mathrm{Cr} /$ UHMWPE Couple in Ringer's Solution: An Approach to Construction of Mechanism and Synergism Maps for Application to Bio-implants, Wear, 2010, 269, p 376-382

42. V. Krakhmalev, On the Abrasion of Ultrafine WC-Co Hardmetals by Small SiC, Tribol. Lett., 2008, 30, p 35-39

43. A. Wank, B. Wielage, H. Pokhmurska, E. Friesen, and G. Reisel, Comparison of Hardmetal and Hard Chromium Coatings under Different Tribological Conditions, Surf. Coat. Technol., 2006, 201, p 1975-1980

44. M.T. Mathew, M.M. Stack, B. Matijevic, L.A. Rocha, and E. Ariza, Micro-abrasion Resistance of Thermochemically Treated Steels in Aqueous Solutions: Mechanisms, Maps, Materials Selection, Tribol. Int., 2008, 41, p 141-149

45. J.F. McCabe and A.R. Ogden, The Relationship Between Porosity, Compressive Fatigue Limit, and Wear in Composite Resin Restorative Materials, Dent. Mater., 1987, 3, p 9-12

46. B. Yin, Y. An, H. Zhou, F. Yan, and J. Chen, Friction and Wear Behaviors of Plasma Sprayed Conventional and Nanostructured WC-12Co Coatings at Elevated Temperature, Adv. Tribol., 2010, 3(IV), p 621-622

47. N. Serres, F. Hlawka, S. Costil, C. Langlade, and F. Machi, An Investigation of the Mechanical Properties and Wear Resistance of NiCrBSi Coatings Carried out by In Situ Laser Remelting, Wear, 2011, 270, p 640-649

48. G. Di Girolamo, L. Pilloni, G. Pulci, and F. Marra, Tribological Characterisation of WC-Co Plasma Sprayed Coatings, J. Am. Ceram. Soc., 2009, 92, p 1118-1124 